International Journal of Engineering \& Technology, 9 (2) (2020) 541-545
International Journal of Engineering \& Technology
SPC
Website: www.sciencepubco.com/index.php/IJET
Research paper

\title{
Conflict matrix as a mechanism of identifying the conflict in emotions of written text
}

\author{
Abbasi Mohsin Manshad 1, 2, *, Abbasi Anees Qumar ${ }^{3,4}$, Beltiukov Anatoly Petrovich ${ }^{1}$, Hussain Lal. ${ }^{2}$ \\ ${ }^{1}$ Udmurt State University, Izhevsk, Russia \\ ${ }^{2}$ University of Azad Jammu \& Kashmir, Muzaffarabad (A.K), Pakistan \\ ${ }^{3}$ Karlsruhe Institute of Technology, Germany \\ ${ }^{4}$ Women University of AJK, Bagh, Pakistan \\ *Corresponding author E-mail: mohsinmanshad@gmail.com
}

\begin{abstract}
Text is a major source of information and is considered as a mechanism of communicating emotions and ideas. The emotion and their analysis from written text gained popularity over recent decades. It has been credited to the growth of information technology and the rapid increase in availability of internet around the globe. In this work, the main idea is to identify the conflict in emotions that exist in the written text. The use of conflict analysis is to identify the contradictory views of people about an object or a topic of discussion. Its existence in text however complicates the process of analysis of emotions from text. This paper describes a mechanism in which the emotions in each pair of sentence are considered as conflicting to each other. The emotional orientation of each pair of sentence is observed to identify the truth-value of the proposed conflict hypothesis. The result of the analysis is summarized using the Conflict matrix. Conflict matrix is a major product of this research that is used to identify the conflicting emotions in text and to measure their characteristics. The results of the experiment were analyzed using the supervised learning techniques along with the Confusion matrix. In methodology and conclusion sections of the paper, the results are discussed in detail.
\end{abstract}

Keywords: Blog of Text; Conflict Matrix; Emotions; Precision; Recall.

\section{Introduction}

Text is a one of the major source to communicate information about an object, place, event, person, or thing. It is available in the form of blogs, social media networks, television as well as in the form of books, magazines, letters, newspapers. Text from online sources is widely used to identify the emotions of people about a particular event, topic, services, product etc. and categorize the text as positively or negatively oriented. Emotion analysis from text is used for the purpose of prediction of future events, to analyze the feedback of people about a product or service, to identify the groups of people with similar interests etc. The existence of contradiction within emotions in text makes the process of analysis more complicated.

By philosopher, the conflict can be of six main types Man to Man, Man vs Self, Man vs Society, Man vs Nature, Man vs Technology, Man vs Fate. In our previous work, we focused on analyzing emotions from text. In addition, we identified the dependencies that exist between them in text. An interface was created for improving the interaction between man and machine using emotional and psycho-linguistic characteristics of text. In this work, the main idea is to develop a mechanism for identifying conflict in emotion before the analysis of text. The main reason for conflict in online text is the purpose of writing the text. Over past years, the online shops are hiring people or some of their own workers for writing positive blogs and feedback about their products. It means that the overall conflict in the emotions of people about a particular product exits because of the conflict of interest or conflict of purpose. Here the false information needs to identify. The goal of coworker is to increase the sale and generate revenue by propagating misleading information. Whereas the purpose of clients from reading a feedback is to obtain the real information about the products or services of shop.

\section{Related work}

The conflict analysis from text and its results were firstly published by Schrodt in mid of 1980s and then in the beginning of 90s [1-5]. In 1984, Weber subsumed the methods for symbolic data analysis under the label of computer-aided content analysis [6]. Initially the purpose of conflict analysis was to made predictive model for conflict identification in symbolic data. Later in 90s, the aim of analysis shifted to the purpose of conflict mediation [7, 8]. In 2000, the warning indicator models were created to prevent conflicts [9]. Over recent decades, social media appears to be the biggest source of available text. The text from social media websites was used to study the structural and dynamic interaction aspects of the multiple groups involved in conflicts [10]. In 2002 (Hammarstr and Heldt) studied the diffusion of interstate military conflict using network analysis methods [11]. While during same year, (Takacs) analyzed the likelihood of intergroup 
conflicts [12]. Social media analysis was used to identify the division of power within the groups and to study their internal dynamics, the nature of decision-making processes [13]. Similarly, the networks were used to identify the online activities related to the extremism and terrorism [14-15]. The text from social media was analyzed to identify the influence of antigovernment networks in generating the conflicting behavior in society [16]. It was used to understand the international conflict and to proposed mechanism for solving them [17]. Recently the research on conflict analysis is used to identify the actors that violet the rules of communication in society and disperse hate speeches, cyber mobbing, and extremism [18]. .Example of such attempts studied by (Leschke and Schwemmer) in online newspaper articles for promoting discrimination against African Americans in the media [19]. The identification of logical relationships and dependencies between emotions in written text provides an efficient mechanism to analyze text and identify its overall polarity [20-24].

\section{Methodology}

This research work proposed a model to identify the conflict in emotions and to identify the intensity of conflicting emotions in the written text. The model was tested and implemented on a text from online blog. The experiment consists of several steps.

1) It begins with the selection of a text for analysis. For this research, a text from online blog was used. The title of the blog was online shopping and its future.

2) In the next phase, the features or characteristics of online shopping were identified in each sentence of the text along with the emotions expressed about them. In case a sentence was inherited from another sentence, it also inherits the features of the root sentence.

3) The sentences expressing the relevant features of online shopping were identified for analysis whereas the irrelevant sentences were filtered out. The filtration of irrelevant sentences improves the performance and accuracy of the algorithm.

4) Now the Hypothesis $(\mathrm{H})$ was applied on each pair of sentence of text $(\mathrm{T})$. Hypothesis is that the emotions in each pair of sentences are contradictory to each other.

5) For identification of the contradiction, the elements of sentence such as emotions and their antonyms were identified using English Word net (https://wordnet.princeton.edu/). The prefixes such as anti, un, non before emotions are identified in each pair of sentence.

6) Similarly, the numerical values such as number, time, date of an event are also analyzed in pair of sentences. The results of the analysis was then recorded in the proposed Conflict matrix.

7) The results from Conflict matrix were analyzed using the supervised leaning technique along with the confusion matrix. In confusion matrix, the accuracy, recall and precision of the results were observed to identify the performance of the proposed algorithm for identification of conflict in pair of sentences.

\section{Experiment}

In this paper, a blog of text was used for experiment. The blog contained the feedback of people about the products and the services provided by them. It was observed that the online shopping gained popularity over recent decade because of its availability and low cost. However, the increase in the number of online shops increase the reliability of doing shopping online. Each online shops has its own mechanism to sell product, getting payment and to deliver product. There are many fake sites for online shopping available on internet. Making payments using bankcards can get very dangerous in some cases. Because of these reasons, people have different experience of doing shopping online. Their opinion about online shopping can be very conflicting. It was observed in the blog that the main features under discussion about online shopping were the cost of products, their quality, delivery time of products, communication with their clients and other services they provided. During the research, a big contrast between the emotions showed by people about the online shopping was observed. It may be because of indifferent behavior (discrimination) of the shop towards its customers. To understand this, the products and their delivery location was also observed. If both are same or near to each other. Then its mean that someone is giving wrong or misleading opinion. A part of the blog of text is presented in the figure 1 below.

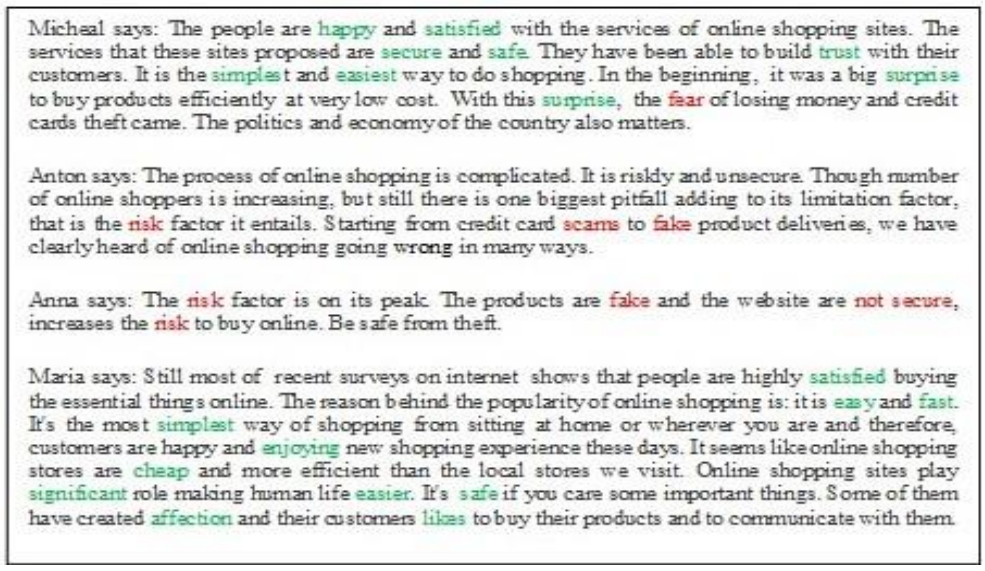

Fig. 1: Blog of Text about Online Shopping and Its Future.

The text was extracted from an online blog and was used by the program for identifying the conflicting emotions in it. The words with red color represents the negative emotions whereas the words with green color represent positive emotions presented in the text.

For analysis of the blog, the text was divided into separate sentences. The features, characteristics of shopping in each sentence and the emotions about them were identified separately. The identified features and their conflicting values were stored in the Conflict matrix. In case of online shopping, the identified features were services, communication, price, delivery period and the quality of product. The sentences that were not relevant to those features filtered out from the text to reduce the size of text and to improve the performance of the program. 
During next phase, the sentences were grouped in pairs and the hypothesis was made that there is a conflict between the two sentences in each pair. To identify the truth-value of the hypothesis, the Conflict matrix was proposed. In the Conflict matrix, each row represents the result of hypothesis about each feature of the online shopping. For representing the structure of the Conflict matrix and its components, six sentences and the relationship between them is presented in the article. The details of the Conflict matrix along with its characteristics are discussed below in table 1 .

Table 1: Conflict Matrix Representing the Truth-Value of Hypothesis H on Each Pair of Sentences

\begin{tabular}{|c|c|c|c|c|c|}
\hline \multicolumn{6}{|l|}{ Conflict Matrix } \\
\hline Topic & \multicolumn{5}{|c|}{ Online shopping and its future } \\
\hline Hypothesis H & \multicolumn{5}{|c|}{ Feature / Component / Characteristics } \\
\hline Sentences & Quality & Delivery & Price & Services & Communication \\
\hline $1 \& 2$ & 1 & - & & - & 1 \\
\hline $2 \& 3$ & 0 & - & 0 & - & - \\
\hline $3 \& 4$ & 1 & - & - & 1 & - \\
\hline $4 \& 5$ & 0 & 1 & - & 0 & 1 \\
\hline $5 \& 6$ & 0 & 0 & 0 & 1 & - \\
\hline $1 \& 3$ & 0 & 0 & 1 & - & 1 \\
\hline $2 \& 4$ & 1 & 1 & 0 & 1 & - \\
\hline $1 \& 4$ & - & - & 1 & 0 & 0 \\
\hline $5 \& 1$ & - & 1 & 0 & - & 1 \\
\hline $2 \& 5$ & 1 & 1 & 0 & 1 & - \\
\hline $3 \& 5$ & - & 1 & 1 & - & 1 \\
\hline $2 \& 6$ & 1 & - & 0 & - & 1 \\
\hline $3 \& 6$ & - & 1 & 0 & 1 & - \\
\hline $4 \& 6$ & 1 & - & 1 & - & - \\
\hline $1 \& 6$ & - & 1 & 0 & 1 & 1 \\
\hline FALSE & 4 & 2 & 8 & 2 & 1 \\
\hline TRUE & 6 & 7 & 4 & 6 & 7 \\
\hline
\end{tabular}

The table 1 above represents the Conflict Matrix of six sentences randomly chosen from text. Conflict Matrix is a product of this research. The two-paired sentences were compared in each row to identify the conflicting emotions in the components of online shopping.

For identifying the emotions from text, the dictionary-based mechanism was used in which there is already a collection of existing emotions as proposed by English Wordnet (https://wordnet.princeton.edu/) . The five components of topic were quality of products, delivery time, price of product, service quality and the communication with the clients. In case the Hypothesis is true and there exists a conflict in emotions about a particular feature of the online shopping in a pair of sentences, the conflict value be set ' 1 ', otherwise ' 0 '. The value ' 1 ' represents the truthfulness of the hypothesis whereas ' 0 'value represent the hypothesis was false. The null value represent by symbol '-' elaborate the non-existence of emotions about a component of online shopping. The complete results of the blog of text used in experiment consists of 300 sentences. The results of hypothesis from conflict matrix explained below in table 2 .

Table 2: Results of Conflict Hypothesis Analysis

\begin{tabular}{|c|c|c|c|c|c|}
\hline \multicolumn{6}{|c|}{ Results of Hypothesis } \\
\hline Component & TRUE & FALSE & Total & $\%$ TRUE & $\%$ FALSE \\
\hline Quality & 7 & 24 & 31 & 22.58 & 77.42 \\
\hline Delivery & 7 & 17 & 24 & 29.17 & 70.83 \\
\hline Price & 5 & 20 & 25 & 20.00 & 80.00 \\
\hline Services & 13 & 21 & 34 & 38.24 & 61.76 \\
\hline Communication & 17 & 5 & 22 & 77.27 & 22.73 \\
\hline
\end{tabular}

From the table 2, truth-value of the hypothesis that there is a conflict of emotions in each pair of sentences is observable. The hypothesis about the components of online shopping such as quality of product is $77.42 \%$ false and $22.58 \%$ true. It means that around $77.42 \%$ opinion about the quality of product in online shopping is same with an exception of $22.58 \%$. Similarly for delivery period of product, 70 , $83 \%$ false and $29.17 \%$ true, for price $80.00 \%$ false and $20.00 \%$ true, other services $61.76 \%$ false and $38.24 \%$ true. For communication with client, there is a high conflict in opinion. Around $77.27 \%$ opinion represents conflict and 22.73 without conflict. The results of conflict matrix are further elaborated in the graph 1 below.

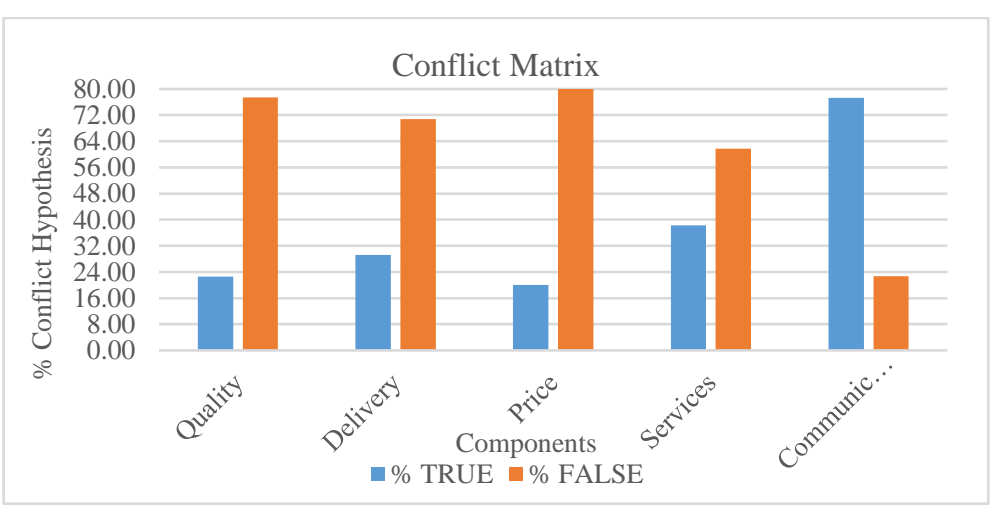

Graph 1: Truth-Value of Each Component of Online Shopping in Conflict Matrix.

From the graph 1, it can be observed that the hypothesis has high truth-value when it is about communication between the client and the sellers of the products in online shopping. It means that the conflict in opinion is very high. Whereas in case of price, the conflict is 
minimum. It means most of the people think the similar way about the prices of the product. Similarly, the value of conflict is low about other components of online shopping. It also explains that the hypothesis about conflict has low truth-value in the whole text.

To analyze the results of the Conflict matrix, the standard confusion matrix was used. Confusion matrix also known as error matrix indicates the classification performance of an algorithm. It uses statistical measures such as accuracy, precision, recall and F-measures to identify the performance of classification algorithm. A typical confusion matrix presented in table 3 below.

Table 3: Confusion Matrix and Its Components

\begin{tabular}{|c|c|c|c|}
\hline \multicolumn{4}{|c|}{ Actual Values } \\
\hline 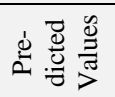 & $\begin{array}{c}\text { Positive } \\
\text { Negative }\end{array}$ & $\begin{array}{c}\text { Positive } \\
\text { TP (True Positive) } \\
\text { FN (False Negative) }\end{array}$ & $\begin{array}{c}\text { Negative } \\
\text { FP (False Positive) } \\
\text { TN (True Negative) }\end{array}$ \\
\hline
\end{tabular}

The TP (True Positive) and TN (True Negative) elaborates that the Truth-values identified by conflict matrix are actual whereas the FN (False Negative) and FP (False Positive) elaborates the errors or misclassification made by conflict matrix during identification of conflict. The confusion matrix is a supervised learning technique where the values of matrix are observed to identify the classification performance of a program or algorithm. The confusion matrices for components of the online shopping are detailed below in table 4 .

Table 4: Confusion Matrix of All Components of Online Shopping

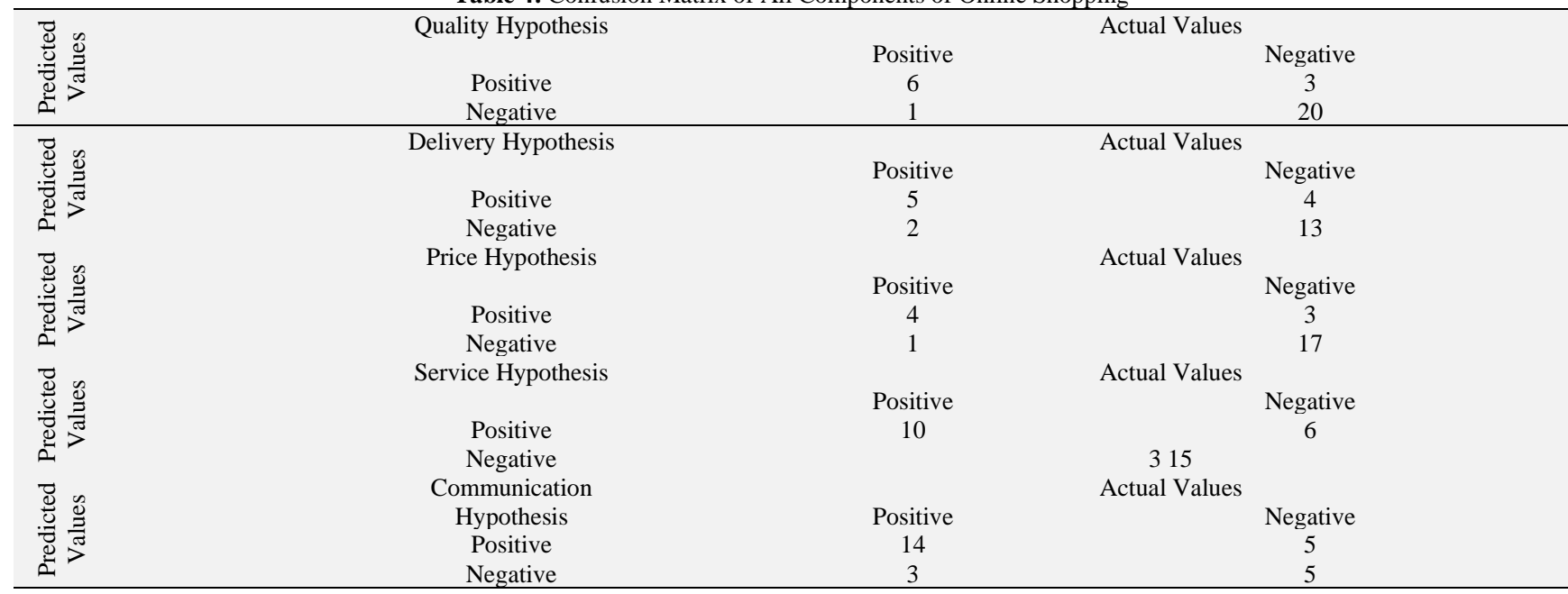

The results of confusion matrix were used to identify the truth-values of the proposed Conflict matrix. The statistical measures such as precision, accuracy, F-measures, recall were used to calculate the performance of the algorithm. These performance measures are detailed below in table 5 .

Table 5: Performance Analysis of Proposed Methodology

\begin{tabular}{|c|c|c|c|c|}
\hline Features/ Characteristics & Accuracy & Recall & Precision & F-Measures \\
\hline Quality & $86.67 \%$ & $85.71 \%$ & $66.67 \%$ & $75.00 \%$ \\
\hline Delivery & $75.00 \%$ & $71.43 \%$ & $55.56 \%$ & $62.50 \%$ \\
\hline Price & $84.00 \%$ & $80.00 \%$ & $57.14 \%$ & $66.67 \%$ \\
\hline Services & $73.53 \%$ & $76.92 \%$ & $62.50 \%$ & $68.97 \%$ \\
\hline Communication & $70.37 \%$ & $82.35 \%$ & $73.68 \%$ & $77.78 \%$ \\
\hline
\end{tabular}

The statistical measure accuracy was used to identify the classification rate of the algorithm. The measure recall is the ratio of the total number of correctly classified positive divide to the total number of positive examples. If the recall has high values then it means that the classes were corrected classified. The value of precision was calculated by dividing the total number of correctly classified positive examples with the total number of predicted positive examples. The high precision elaborates that the positive labelled examples were classified correctly. F-measures uses harmonic means for extreme values. It represents the value of recall and precision. It is equal or near to smallest value of one of them.

From the analysis of confusion matrix, the high accuracy of the results of the proposed algorithm is observable. It elaborates the performance and effectiveness of the proposed algorithm to identify the conflict in text using the Conflict matrix.

\section{Conclusions}

It was observed that the identification of conflict in emotions plays an important role in identifying the overall polarity of the text document. It facilitates the process of the identification of differentiating opinion about the same topic in the text. The false information about a particular subject in text was judged using the conflict in numbers, digits, time or place of an event. The similar emotions elaborates the truthfulness of information about a subject. It was used for inference of reliable information from text. In future, it will be used to predict the conflict about a particular event or topic in text. Similarly, the identification of conflict in emotions will be used to identify the reason for conflicts and to avoid them in future.

\section{References}

[1] Schrodt, PA (1984), Artificial intelligence and international crisis: An application of pattern recognition, In Annual meeting of the international studies association, Washington, DC, Connecticut: International Studies Association. 
[2] Schrodt, PA (1987), Classification of interstate conflict outcomes using a bootstrapped CLS algorithm, In Annual Meeting of the International Studies Association, Washington, DC, Connecticut: International Studies Association.

[3] Schrodt, PA (1990), Predicting interstate conflict outcomes using a bootstrapped ID3 algorithm, Political Analysis 2, 31-56. https://doi.org/10.1093/pan/2.1.31.

[4] Schrodt, P A., "Prediction of interstate conflict outcomes using a neural network", Social Science Computer Review, Vol. 9, No. 3 (1991), pp. 359380. https://doi.org/10.1177/089443939100900302.

[5] Schrodt, PA (1997), Early warning of conflict in Southern Lebanon using Hidden Markov Models. In Annual meeting of the international studies association, Washington, DC. Connecticut: International Studies Association.

[6] Weber RP., "Computer-aided content analysis: A short primer". Qualitative Sociology, Vol. 7, No.12, (1984), pp. 126-147. https://doi.org/10.1007/BF00987112.

[7] Trappl R, Fürnkranz J, Petrak J, "Digging for peace: Using machine learning methods for assessing international conflict databases", In W. Wahlster (ed.) Proceedings of the $12^{\text {th }}$ European conference on Artificial Intelligence, Chichester: Wiley, (1996), 453-57.

[8] Trappl R, Fürnkranz J, Petrak (1997), Machine learning and case-based reasoning: Their potential role in preventing the outbreak of wars or in ending them. In G. https://doi.org/10.1007/978-3-7091-2668-4_13.

[9] Gerner DJ, Schrodt PA., "Cluster-based early warning indicators for political change in the contemporary Levant", American Political Science Review Vol. 94, No. 4, (2000), pp. 803-818. https://doi.org/10.2307/2586209.

[10] Wolfe AW, "Network thinking in peace and conflict studies", Peace and Conflict Studies, Vol. 11, No. 1, (2004), pp. 4-10. https://doi.org/10.1207/s15327949pac1101_6.

[11] Hammarstr M, Heldt B, "The diffusion of military intervention: Testing a network position approach", International Interactions, Vol. 28, No. 4, (2002), pp. 355-377. https://doi.org/10.1080/03050620214758.

[12] Takács K (2002), Social network and intergroup conflict, PhD thesis, University of Groningen.

[13] Kramer CR (2017), Network theory and violent conflicts, Basingstoke, Palgrave Macmillan. https://doi.org/10.1007/978-3-319-41393-8.

[14] Perliger A, Pedahzur A, "Social network analysis in the study of terrorism and political violence", Political Science and Politics, Vol. 44, No. 1, (2011), pp. 45-50. https://doi.org/10.1017/S1049096510001848.

[15] Deutschmann, E, "Between collaboration and disobedience. The behavior of the Guantánamo detainees and its consequences", Journal of Conflict Resolution, Vol. 60, No. 3, (2016), pp. 555-582. https://doi.org/10.1177/0022002714545331.

[16] Gleditsch KS, Metternich NW, Ruggeri A, "Data and progress in peace and conflict research", Journal of Peace Research, Vol. 51, No. 3, (2014), pp. 301-314. https://doi.org/10.1177/0022343313496803.

[17] Trappl R, Hörtnagl E, Rattenberger J, Schwank N, Bercovitch J, "Machine learning methods for better understanding, resolving, and preventing international conflicts", In R. Trappl (ed.) Programming for peace, Dordrecht: Springer, Vol. 2, (2006), pp. 251-318 https://doi.org/10.1007/1-40204390-2 11.

[18] Fischer PD, Schwemmer C, Fischbach K., "Collective sense making in times of crisis: Connecting terror management theory with twitter reactions to the berlin terrorist attack", Computers in Human Behavior, Vol. 100, (2019), pp. 138-151. https://doi.org/10.1016/j.chb.2019.05.012.

[19] Leschke JC, Schwemmer C (2019), Media bias towards African Americans before and after the Charlottesville rally, In Weizenbaum conference (p. 10), DEU.

[20] Beltiukov AP, Abbasi MM, "Logical analysis of Emotions in Text from Natural language", Vestnik Udmurtskogo Universiteta. Matematika. Mekhanika. Komp'yuternye Nauki, Ижевск, Vol.1, No. 29, (2019), pp. 106-116. https://doi.org/10.20537/vm190110.

[21] Abbasi MM, Beltiukov AP, “Analyzing emotions from text corpus using word space CSIT'2018”, Proceedings of the 20th International Workshop on Computer Science and Information Technologies ,Varna- Bulgaria, Industry 4.0, Vol. 3, No. 4, (2018), pp.161-164.

[22] Abbasi MM, Beltiukov AP, "Identifying the strength of emotions in relation with the topic of text using Word space", Proceedings of the 21 $1^{\text {th }}$ international workshop on computer science and information technologies, Austria, Vienna, Journal of Atlantis Highlights in Computer Sciences, Vol. 3, (2019), pp. 1-5. https://doi.org/10.2991/csit-19.2019.1.

[23] Abbasi MM, Beltiukov AP, Hussain Lal, Abbasi AQ, "Analysis of emotions from texts for managing society", Infocommunication technologies Journal, Academy of Telecommunications and Informatics, Samara, Vol. 2, No.17, (2019), pp. 246-254. https://doi.org/10.18469/ikt.2019.17.2.15.

[24] Abbasi MM, Beltiukov AP, "Summarizing emotions from text using Plutchik wheel of emotion", $7^{\text {th }}$ All Russian Conference on Information technology for intelligent decision-making support (ITIDS), Ufa, Russian Federation, Vol. 166, (2019), pp. 291-294. 